\title{
Serangan Hama Pada Tegakan Ekaliptus (Eucalyptus alba) di Kawasan Hutan Lindung Gunung Nona Kota Ambon
}

\author{
Fransina S. Latumahina ${ }^{1}$, Mohamad Lihawa ${ }^{2}$ \\ ${ }^{1}$ Jurusan Kehutanan Fakultas Pertanian Universitas Pattimura Ambon \\ Jl. Ir. M. Putuhena, Kampus Poka Ambon, 97233. \\ 2 Jurusan Agroteknologi Fakultas Pertanian Universitas Negeri Gorontalo \\ Korespondensi Email : fransina.latumahina@yahoo.com
}

\begin{abstract}
ABSTRAK
Ekaliptus (Eucaliptus alba) dalam Hutan Lindung Gunung Nona berperan sebagai tanaman pelindung dari erosi dan banjir yang sering terjadi dalam kawasan, namun dalam dasawarsa terakhir keberaadaan tegakan Ekaliptus mengalami tekanan akibat serangan hama dengan tingkat kerusakan yang tinggi akibatnya tutupan kawasan dengan tanaman ini menjadi berkurang. Penelitian dilaksanakan untuk mengetahui jenis hama, intensitas kerusakan dan luas serangan hama pada tegakan Eucalyptus alba di kawasan Hutan Lindung Gunung Nona Kota Ambon dengan menggunakan metode survey dengan intensitas sampling sebebesar $10 \%$ pada 20 pohon sampel. Pengamatan dilakukan pada tegakan Ekaliptus tingkat pohon dari akar hingga daun dengan melihat gejala dan tanda - tanda serangan hama. Hasil Penelitian menemukan tiga jenis hama yakni Ulat Grayak (Spodoptera sp). Intensitas kerusakan tertinggi akibat serangan hama pada tanaman Ekaliptus dalam Hutan Lindung Gunung Nona Kota Ambon akibat serangan Ulat Grayak (Spodoptera sp) sebesar 72,37\% tergolong kriteria berat, Ulat Jengkal (Hyposidra talaca) sebesar 19,22\% dan tergolong kriteria sedang dan Rayap Tanah (Macrotermes Gilvus Hagen) sebesar 7,09\% tergolong kriteria ringan. Luas serangan yang ditimbulkan akibat serangan ketiga jenis hama ini yakni Ulat Grayak (Spodoptera $S p$ ) sebesar 67,7\% tergolong kriteria berat, Ulat Jengkal (Hyposidra talaca) sebesar 40,9\% tergolong kreiteria sedang dan Rayap Tanah (Macrotermes Gilvus Hagen) sebesar $15,9 \%$ tergolong kriteria ringan.
\end{abstract}

Kata Kunci : Eucapliptus alba, , Intensitas serangan, luas serangan

\section{Pest Attack on Eucalyptus alba in Gunung Nona Protected Forest Area, Ambon City}

\begin{abstract}
Eucalyptus (Eucalyptus alba) in Gunung Nona protected -forest play important roles as protective plants of erosion and flooding that often occurs in the region. However, in the last decade, the existence of the Ekaliptus stand has been under pressure due to pests with high levels of damage reducing forest cover. The study was conducted to determine the type of pests, the intensity of damage and the extent of pest attack in the Eucalyptusalba in Gunung Nona Forest. The study method was survey with $10 \%$ of 20 sample trees sampling intensity. Observations on tree-level Eucalyptus stands were conducted from roots to leaves by looking at the symptoms and signs of pest attacks. The research found three types of pests, namely Ulat Grayak (Grayak Caterpillars). The highest intensity of damage is $72,37 \%$ due to pest attacks by Spodoptera sp, 19,22\% or moderate criteria by Hyposidra talacaand and $7.09 \%$ or mild criteria by Macrotermes Gilvus Hagen. While the extent of pest attack are $67,7 \%$ by Spodoptera $S p, 40,9 \%$ by Hyposidra talaca, and 15,9\% by Macrotermes gilvus Hagen which is classified as strict, medium, and mild criteria, respectivelly.
\end{abstract}

Keywords: Eucapliptus alba, intensity of attacks, widespread attack 


\section{PENDAHULUAN}

Hutan adalah suatu asosiasi tumbuhan di mana pohon-pohon atau tumbuhan berkayu lainnya secara pre dominan menempati wilayah yang luas dan keadaannya cukup rapat sehingga mampu menciptakan iklim yang berbeda dengan di luar hutan. Hutan sebagai salah satu sumber kekayaan alam di dalamnya terkandung bahan-bahan berupa kayu dan hasil lainnya yang dapat di manfaatkan untuk kesejahtraan masyarakat serta sumber devisa bagi pembangunan nasional ${ }^{[1]}$. Dalam dasawarsa terakhir tingkat kerusakan hutan semakin meningkat dari tahun ke tahun sejalan dengan meningkatnya jumlah penduduk yang cukup pesat disekitar kawasan hutan lindung. Hutan lindung Gunung Nona Kota Ambon memiliki fungsi dan peran yang cukup besar bagi masyarakat Kota Ambon, oleh karena itu upaya perlindungan terhadap kawasan perlu dilakukan guna menjaga fungsi dan peran kawasan. Serangan hama dalam kawasan dapat mengakibatkan terhambatnya pertumbuhan pohon bahkan dapat mengakibatkan kematian pohon akibatnya kwalitas dan kwantitas hasil hutan akan mengalami penurunan dan pada gilirannya berimbas pada fungsi dan peran hutan lindung. Salah satu penyebab kerusakan hutan monokultur adalah akibat serangan hama maupun penyakit, sehingga menyebabkan terhambatnya pertumbuhan pohon bahkan dapat mengakibatkan kematian pada pohon inang sehingga dapat menurunkan kualitas dan kuantitas hasil hutan ${ }^{[2]}$.

Tanaman Eucalyptus alba merupakan salah satu tanaman terpilih dalam kegiatan penghijauan dan pengembangan Hutan Tanaman Industri (HTI) karena jenis ini memiliki pertumbuhan yang relatif cepat, dapat tumbuh pada lahan kritis dan daerah yang beriklim kering terutama lahan yang miskin unsur hara dan dapat ditanam dengan jarak rapat tanpa mengurangi riapnya. Eucalyptus alba dapat dimanfaatkan sebagai bahan baku industri, Pulp, kayu pertukangan, kayu perkapalan dan minyak astiri .

Ekaliptus dapat tumbuh cepat dan mudah beradaptasi pada berbagai lahan termasuk pada daerah-daerah yang beriklim kering dan tanah yang sangat miskin hara. Umumnya kerusakan Ekaliptus akibat serangan hama pada daun, pucuk, pengerek batang serta penghisap cairan daun dan beberapa serangan tertinggi pada akar akibat kehadiran rayap tanah. Gejala kerusakan yang umum terjadi pada batang dan cabang berupa gembol dan atau lubang gerek. Apabila larva masih aktif di dalam, maka akan terlihat adanya serbuk gerek berbentuk bulatan-bulatan kecil berdiameter 1-2 mm dengan warna coklat kemerahan yang terkumpul di bawah pohon bersangkutan. Larva yang telah membuat lubang, akan terus menggerek sampai ke bagian xylem dan terus bergerak ke arah vertikal, dan atau membuat liang gerek melingkar batang. Adanya liang gerek terutama yang melingkar batang, akan membuat pohon bersangkutan menjadi rentan terhadap tiupan angin, sehingga sering kali dijumpai adanya pohon-pohon yang mengalami patah tajuk atau patah batang $^{[3]}$. Serangan penggerek banyak terjadi pada pohon yang berumur antara 2-3 tahun, sementara untuk pohon yang masih berumur 1 tahun ke bawah, relatif belum banyak terjadi serangan. L invasa dari Ordo Hymenoptera. Dari Queensland, Australia telah banyak dilaporkan menyerang dan merusak tanaman Eucalyptus di beberapa negara di Timur Tengah, Israel, Sri Lanka, Kenya dan Vietnam. Hama ini mempunyai tingkat serangan sebesar $30-100 \%$ dan dilaporkan telah menyebabkan ledakan populasi di Gujarat, India ${ }^{[4]}$. Berdasarkan permasalahan di atas, maka perlu dilakukan penelitian yang mendetail untuk mengetahui jenis hama dan intensitas kerusakan yang ditimbulkan pada tanaman Eucalyptus alba di kawasan Hutan Lindung Gunung Nona Kota Ambon sehingga dapat ditentukan teknik pencegahan maupun 
pengendalian yang tepat secara efektif dan efisien.

\section{BAHAN DAN METODE}

Penelitian dilaksanakan pada kawasan hutan Lindung Gunung Nona Kota Ambon selama tiga (3) bulan yakni penelitian lapangan pada bulan Oktober - Desember 2019 dan dilanjutkan dengan penelitian laboratorium Hutan Lindung Gunung Nona tergolong iklim tipe B (Bulan Basah) dengan curah hujan pertahun sebesar 2,8396 mm dengan rata rata hujan pertahun adalah 187,90 hari. Suhu udara makro di Kota Ambon mencapai 28, oC dan suhu mikro dalam kawasan 26, 5 oC dengan kelembaban mikro $70 \%$. Kondisi lahan dalam areal hutan lindung Gunung Nona adalah bergelombang hingga curam dengan kelerengan 8 hingga $>45 \%$ dengan jenis tanahnya adalah batuan beku (granit, kuarsa, peridotit ) dan batuan sedimen ( Batu Pasir dan Koral)

\section{Prosedur Penelitian}

Penelitian menggunakan metode survei, dengan pengambilan sampel pada areal seluas 1 Ha dengan 200 pohon populasi. Dari populasi tanaman diambil sampel sebesar $10 \%$ atau 20 tanaman secara acak yang terbagi atas 5 blok yang tiap bloknya diambil 4 tanaman sebagai sampel, karena jarak tanam tanaman tidak terartur yakni $2 \times 3$ dan $3 \times 3 \mathrm{~m}$. Dari 20 pohon sampel dilakukan pengamatan terhadap daun, dengan menggunakan sistem arah mata angin (utara, barat, timur, selatan). Untuk mempertinggi tingkat ketelitian pengambilan data pada setiap pohon sampel khususnya pada daun dilakukan pengamatan berdasarkan tingkatan tajuk. Untuk memudahkan dalam pengolahan data, maka setiap tanaman terlebih dahulu ditentukan intensitas serangannya berdasarkan keadaan tajuk tanaman, tingkat serangan dan nilai/skor yakni :

Tabel 1. Skoring Penentuan Intensitas Serangan Hama

\begin{tabular}{llc}
\hline \multicolumn{1}{c}{ Keadaan Tajuk Tanaman } & Tingkat Serangan & Nilai/Skor \\
\hline Sehat & Sehat & 0 \\
Tajuk terserang/mati $1-24 \%$ & Ringan & 1 \\
Tajuk terserang/mati $25-49 \%$ & Sedang & 2 \\
Tajuk terserang/mati 50-74\% & Berat & 3 \\
Tajuk terserang/mati $75-100 \%$ & Sangat berat & 4 \\
Tajuk dan batang tanaman mati & Mati & 5 \\
\hline
\end{tabular}

Penentuan Tingkat kerusakan pohon akibat serangan hama dapat dilihat pada Tabel 2

Tabel 2. Penentuan Tingkat Kerusakan Pohon Akibat Serangan Hama

\begin{tabular}{cl}
\hline $\begin{array}{c}\text { Intensitas Serangan } \\
(\%)\end{array}$ & Kondisi Tanaman \\
\hline $0-1$ & Sehat \\
$2-25$ & Ringan \\
$26-50$ & Sedang \\
$51-75$ & Berat \\
$76-100$ & Sangat Berat \\
\hline
\end{tabular}

\section{Pelaksanaan Penelitian}

Penelitian dilaksanakan dalam dua tahap yaitu penelitian lapangan dan penelitian laboratorium. Penelitian lapangan dilaksanakan pada 10 jalur pengamatan berukuran panjan 100 meter dan lebar 10 meter dengan jaraj antara jalur 10 meter untuk mengumpulkan data primer dan data sekunder. Data primer meliputi jenis hama, gejala serangan, kondisi iklim mikro, dan kondisi topografi. Data sekunder meliputi kondisi iklim makro untuk wilayah Kota Ambon yakni suhu udara, kelembaban dan intensitas cahaya yang diperoleh dari stasiun meteorologi dan Geofisika Kota Ambon. 
Penelitian labolatorium dilaksanakan pada Laboratorium Silvikultur Jurusan Kehutanan Fakultas Pertanian Unpatti Ambon dengan bantuan kunci determinasi serangga.

\section{HASIL DAN PEMBAHASAN}

\section{Jenis Hama yang Menyerang}

Penelitian terhadap tanaman Eucalyptus urophylla dalam kawasan Hutan Lindung Gunung Nona Kota Ambon menunjukan adanya kerusakan yang cukup berat akibat serangan hama. Berdasarkan hasil inventarisasi dan identifikasi melalui pengamatan laboratorium dengan menggunakan kunci determinasi serangga, maka di temukan tiga jenis hama yang menjadi penyebab kerusakan pada tanaman Eucalyptus urophylla di lokasi penelitian yakni Ulat Grayak (Spodoptera $S p$ ), Ulat Jengkat (Hyposidra talaca), dan Rayap Tanah (Macrotermes gilvus Hagen).

\section{Ulat Grayak (Spodoptera Sp)}

Ulat Grayak termasuk Famili Noctuidae, ordo Lepidoptera. Hasil penelitian dilapangan menemukan puluhan ulat muda dan ulat yang sudah tua. Ulat muda terlihat bergerombol dan merekatkan diri pada helaian daun bagian pucuk Ekaliptus dan telah mengeluarkan sutera dari mulutnya. Ulat muda berwana hijau muda dengan punggung bergaris hijau tua serta kepala berwarna kuning terang. Ulat yang tua, ditemukan disekitar pangkal akar berupa pupa berwarna coklat kehitaman, memiliki rambut pada punggung yang bergaris coklat dengan kepala berwarna merah kecokelatan. Pupa ditemukan pada serasah disekitar gulma. Gejala serangan di lapangan terlihat ulat muda memakan jaringan permukaan daun hingga daun berubah wana menjadi kuning dan sehingga daun mengering, sedangkan ulat tua memakan jaringan daun pada bagian pucuk daun. Dilapangan ditemukan semua tahapan perkembangan Ulat Grayak dalam jumlah yang bervariasi yakni ulat, kepompong, ngengat, dan telur. Ulat grayak betina meletakkan telur secara berkelompok pada permukaan daun, dimana tiap kelompok telur terdiri sekitar $350-400$ butir telur per kelompoknya.

\section{Ulat Jengkal (Hyposidra talaca)}

Hama ini termasuk dalam famili Geometridae, ordo Lepidoptera. Hasil di lapangan menemukan puluhan ekor ulat jengkal sedang merayap pada tulang daun hingga ranting pohon. Hama ini sangat mudah dikenali dalam kawasan hutan Gunung Nona karena selalu berpindah tempat tiap 5 menit dengan cara jalan seperti orang sedang menjengkal tanah. Pengamatan lapangan menemukan ulat muda berwarna coklat dengan bintik putih yang melingkari tubuh dan ulat yang lebih tua ditemukan berwarna hijau coklat. Pada beberapa pohon ditemukan telur ulat secara berkelompok pada bagian bawah daun, sementara pupa ditemukan dalam tanah pada kedalaman $2-5 \mathrm{~cm}$. Ulat jengkal menyerang daun dan pucuk daun hingga berlubang-lubang dan pucuk tanaman menjadi gundul, sehingga tertinggal tulang daunnya saja pada pengamatan hari ke 20 .

Gejala serangan berupa daun yang berlubang-lubang, karena ulat muda senang sekali memakan jaringan diantara tulang daun, sedangkan ulat tua lebih menyukai seluruh bagian daun dan memakanya hingga tersisa tulang tulang daun. Ulat jengkal sangat aktif pada siang hari pada saat suhu udara berkisar antara 37 - 39 0C namun ketika suhu udara meningkat diatas 40 Oc sudah sulit menemukannya diatara ranting pohon. Pada saat malam hari ulat ini bersembunyi diantara dedaunan dan celah ranting.

\section{Rayap Tanah (Macrotermes Gilvus Hagen)}

Pengamatan lapangan menemukan rayap dari famili Termitidae, ordo isoptera pada pangkal batang dan perakaran dengan jumlah mencapai ratusan ekor dengan ciri khas pada kepala terdapat lubang kecil 
(fontanel) dan sepasang mata mejemuk yang sederhana, sepasang antena dan sepasang mandibel. Gejala serangan sangat mudah ditemukan di permukaan batang hingga perakaran. Pada saat penelitian terlihat adanya penumpukan tanah yang dimulai dari pangkal batang sampai ketinggian 1- $5 \mathrm{~m}$ diatas tanah dengan jumlah telur \pm 16.000 perhari. Ditemukan pula tubuh Rayap dari kasta pekerja ( instar laron ) berukuran $4 \mathrm{~cm}$ dengan panjang sayap rata - rata $6,8-7,8 \mathrm{~cm}$. Rayap dapat ditemukan di serasah, cabang yang patah dan kerak tanah yang menutup kulit pohon ke arah vertikal [3]. Rayap ditemukan pada ketinggian 390 m - 400 m dpl dalam kawasan Gunung Nona. Penemuan ini sesuai dengan pendapat bahwa penyebaran rayap Macrotermes Gilvus Hagen berhubungan dengan suhu dan curah hujan sehingga sebagian besar jenis rayap terdapat di dataran rendah tropika dan sebagian di temukan di dataran tinggi. Namun demikian, tidak menutup kemungkinan rayap menyebar tidak hanya pada dataran rendah tetapi juga di dataran tinggi ${ }^{[5][6]}$.

\section{Intensitas Kerusakan dan Luas Serangan Hama}

Intensitas kerusakan tertinggi akibat serangan hama pada tanaman Ekaliptus dalam Hutan Lindung Gunung Nona Kota Ambon akibat serangan Ulat Grayak (Spodoptera sp) sebesar 72,37 \% tergolong kriteria berat, Ulat Jengkal (Hyposidra talaca) sebesar 19,22 \% dan tergolong kriteria sedang dan Rayap Tanah (Macrotermes Gilvus Hagen) sebesar 7,09 \% tergolong kriteria ringan. Luas serangan akibat serangan ketiga jenis hama yakni Ulat Grayak (Spodoptera sp) sebesar $67,7 \%$ tergolong kriteria berat, Ulat Jengkal (Hyposidra talaca) sebesar 40,9\% tergolong kreiteria sedang dan Rayap Tanah (Macrotermes Gilvus Hagen) sebesar 15,9 $\%$ tergolong kriteria ringan.

Tingkat kerusakan dan luas serangan yang tinggi dari Ulat Grayak pada tegakan Ekaliptus diduga karena faktor ketersediaan ekaliptus sebagai sumber makanan utama dalam jumlah yang banyak sehingga mudah diperoleh, dan tidak adanya serangga predator dalam kawasan sehingga memudahkan hama ini untuk berekspansi. Areal penelitian yang merupakan areal tanaman monokultur juga berkontribusi terhadap tingganya serangan hama ini,karena tidak ditemukan jenis tanaman lain disekitar areal Ekaliptus, karena Ulat grayak merupakan jenis hama polyphagus yang umumnya menyerang daun tanaman kacang-kacangan, jagung, padi, bawang, selada, sawi, kapas, tebu, kedelai, dan tembakau ${ }^{[7]}$. Serangan ulat grayak ditemukan terjadi di malam hari karena mereka aktif di waktu tersebut, hal ini juga turut mempengaruhi intensitas serangan karena pada saat malam hari tidak ditemukan aktivitas manusia di sekitar ataupun dalam kawasan hutan lindung. Diduga kehadiran manusia ikut mempengaruhi gerak - gerik dari jenis ini karena pada siang hari mereka bersembunyi di bagian bawah daun, dan tidak melakukan aktivitas makan secara sporadis. Akibat serangan, daun berlubang secara tidak beraturan dan menghambat proses fotosintesis.

Serangan rayap tanah tergolong ringan, disebabkan karena umur Eucalyptus urophylla telah tergolong tua 20 - 35 tahun, sehingga menyulitkan rayap untuk melakukan serangan pada batang maupun akar. Kondisi iklim makro dan mikro habitat hutan lindung diduga berpengaruh terhadap kehadiran rayap. Pada saat penelitian rata rata suhu udara mikro mencapai 40oc dengan tingkat kelemababan yang rendah sebesar $70 \%$ dan diduga tidak sesuai dengan kebutuhan rayap Macrotermes, sehingga pada saat penelitian tidak banyak ditemukan karena rayap hanya tinggal dalam sarang dan tidak melakukan serangan karena suhu udara yang terlalu panas yang menembus permukaan tanah. Hal ini dapat dimengerti, karena rayap adalah serangga yang memiliki kulit tipis yang rentan terhadap proses dehidrasi oleh udara kering sehingga rayap membutuhkan kelembaban yang stabil. Suhu berperan dalam distribusi dan aktivitas rayap saat mencari makan ${ }^{[8]}$. Bilamana suhu permukaan tanah 
terlalu panas atau terlalu dingin rayap tidak melakukan foraging ${ }^{[9]}$.

Luas sarang rayap juga berpengaruh terhadap akitivitas rayap, dimana ditemukan hanya satu sarang rayap pada jalur ke dua dari 10 jalur pengamatan. Faktor lingkungan yang utama mempengaruhi distribusi rayap antara lain temperatur, dan kelembaban, sementara itu faktor lain yang mendukung adalah curah hujan, struktur tanah dan vegetasi ${ }^{[10]}$. Besar kecilnya sarang juga diduga berpengaruh terhadap insensitas serangan dan luasan. Vegetasi yang tumbuh disekitar sarang Macrotermes akan menjadi santapan rayap. Kawasan dengan vegetasi pohon yang memiliki kayu awet tinggi mengandung banyak senyawa toksik yang merupakan hasil dari metabolit sekunder maka akan memiliki sarang berukuran kecil, sementara kawasan dengan vegetasi pohon yang memiliki kelas kayu awet rendah maka kandungan senyawa toksik sangat sedikit sehingga akan memiliki sarang berukuran besar ${ }^{[11]}$. Serangan Ulat Jengkal dengan intensitas serangan sedang diduga karena faktor ketersedian jumlah makanan berupa daun ekaliptus dalam jumlah yang banyak sehinga mampu memenuhi kebutuhan makan jenis ini. Beberapa laporan penelitian menyebutkan bahwa selain makan Ekalipus jenis ini juga memakan bibit Kranji [12], tanaman Jarak Pagar, pohon Trembesi, tanaman Sengon, tanaman, tanaman kakao tanaman teh, tanaman murbai ${ }^{[13]}$. Ulat jengkal dalam perkembang biakannya termasuk dalam golongan serangga Holometabola, yaitu kelompok serangga yang mengalami metamorfosis sempurna. Faktor iklim mikro berupa suhu udara dan kelembaban udara diduga sesuai untuk perkembangbiakan larva. Fluktuasi populasi ulat jengkal sejalan dengan perubahan intensitas pembentukan pucuk daun muda. Apabila pucuk daun tanaman yang terbentuk banyak, maka populasi ulat jengkal akan meningkat.Namun, apabila pucuk daun tanaman yang terbentuk sedikit, maka populasi ulat jengkal juga akan sedikit. Pada saat penelitian ditemukan banyak pucuk muda dari Daun Ekaliptus yang baru bermunculan, diduga ikut berperan terhadap kehadiran hama ini di areal hutan lindung. Ulat jengkal atau dikenal juga dengan sebutan ulat kilan sangat menyukai daun muda atau pucuk. Pada serangan yang hebat, ulat ini akan menghabiskan seluruh daun pada bibit dan menyebabkan kematian ${ }^{[14]}$. Suatu penelitian menunjukkan bahwa larva muda dari ulat ini mampu merusak sekitar 5\% - 10\% bibit adas berumur 3 bulan, sedangkan larva dewasa mampu menyebabkan kerusakan hingga 90\% pada bibit yang sama dalam waktu 1 (satu) hari [15].

\section{KESIMPULAN}

1. Hama yang menyerang tanaman Eucaluptus urophylla di kawasan Hutan Lindung Gunung Nona adalah Ulat Grayak (Spodoptera sp.) dan Ulat Jengkal (Hyposidra talaca) serta Rayap Tanah (Macrotermes gilvus Hagen) sebagai hama perusak akar dan batang.

2. Intensitas kerusakan tertinggi akibat serangan hama pada tanaman Ekaliptus dalam Hutan Lindung Gunung Nona Kota Ambon akibat serangan Ulat Grayak (Spodoptera Sp) sebesar 72,37\% tergolong kriteria berat, Ulat Jengkal (Hyposidra talaca) sebesar 19,22\% dan tergolong kriteria sedang dan Rayap Tanah (Macrotermes Gilvus Hagen) sebesar 7,09\% tergolong kriteria ringan.

3. Luas serangan yang ditimbulkan akibat serangan ketiga jenis hama ini yakni Ulat Grayak (Spodoptera Sp) sebesar 67,7 \% tergolong kriteria berat, Ulat Jengkal (Hyposidra talaca) sebesar 40,9\% tergolong kreiteria sedang dan Rayap Tanah (Macrotermes Gilvus Hagen) sebesar $15,9 \%$ tergolong kriteria ringan.

4. Faktor penyebab kehadiran ketiga jenis hama dalam hutan lindung Gunung Nona yakni ketersediaan makanan ( pohon ekaliptus), suhu dan kelembaban udara mikro yang sesuai, serta tidak adanya predator dalam kawasan. 


\section{DAFTAR PUSTAKA}

[1] Tjoa, M., Bone, I., Apono, H. S. E.S., Kastanya, A., Resosudarmo, I.A. and N. A. Utomo. 2019. Implementation of Kph Policies Within Indigenous Agroforestry Systems of Buru Island. Moluccas 14 (6): 325-334.

[2] Hidayah, H.N., Irawan, A. and I. Anggraini,. 2017. Serangan Ulat Jengkal (Hyposidra talaca Wlk.) Pada Bibit Pakoba (Syzygium luzonense (Merr.) Merr.) Di Persemaian. Agrologia 6 (1): 37-43.

[3] Subekti, N., Duryadi, D., Nandika, D., Surjokusumo, S. and S. Anwar. 2008. Distribution and Morphology Characteristic of Macrotermes gilvus Hagen in The Natural Habitat. J. Ilmu dan Teknol. Has. Hutan 1(1): 27-33.

[4] Nuraeni, Y., Latumahina, F.S., Cahyono, T.D. and H. S. Nuroniah. 2020. Caterpillar Bag As Pests At Sengon ( Falcataria Moluccana ( Miq .) Barneby And J . W Grimes ) At Forest Area With Special Purpose (KHDTK )," 9 (2): 3884-3887.

[5] Latumahina, F and G. Mardiatmoko. 2019. The Effect of Climate Change on Abundance and Diversity of Ant in Tuhaha Forest at Mollucas Province on Indonesia. Int. J. Curr. Microbiol. Appl. Sci., 8(5): 2397-2408.

[6] Latumahina, F., Borovanska, M., Musyafa., Sumardi., Putra,N.S. and M. Janda.2015. Ants of Ambon Island Diversity survey and checklist. Zookeys 472: 43-57.

[7] Tanaman, D.P and F. Pertanian. 2016. Hama utama teh dan musuh alaminya pada perkebunan teh rakyat dan perkebunan teh perusahaan negara abdul aris pradana.

[8] Sila, M. 2009. Perlindungan dan pengamanan hutan. Lab. Perlindungan dan Serangga Hutan, pp. 56-59.

[9] Prasetyo, A.E., Rozziansha, T.P.A., Muhayat, M. and R. D. de Chenon. 2019. Gejala serangan dan tingkat serangan Sparganobasis subcruciata Marshall sebagai hama baru pada kelapa sawit di Indonesia bagian timur. J. Entomol. Indones 16(1): 41.

[10] Defitri, Y., Nengsih, Y. and H. Saputra. 2017. Intensitas Serangan Hama Ulat Api (Setothosea asigna) Pada Tanaman Kelapa Sawit (Elaeis guineensis. Jacq) Di Kecamatan Tebo Tengah Kabupaten Tebo. J. Media Pertan 2(1): 16.

[11] Prasetyo, A.E. and A. Susanto. 2019. The Insecticide Effect To The Activity And Emergence of Elaeidobius kamerunicus Faust (COLEOPTERA: CURCULIONIDAE) On Oil Palm (Elaeis guineensis Jacq.) Male Inflorescence. J. Penelit. Kelapa Sawit 27(1): 13-24.

[12] Hariance, R. Febriamansyah, R. and F. Tanjung. 2015. Agribisnis Perkebunan Rakyat Kopi Robusta Di Kabupaten Solok. J. AGRISEP 14(1): 11-25.

[13] Anggraeni, I. and N. Mindawati. 2011. Gmelina (Gmelina arborea Roxb .) Di Hutan Rakyat. Private Forest Land, pp. 85-91.

[14] Herdiana, N. 2010. Potensi Serangan Hama Tanaman Jati Rakyat dan Upaya Pengendaliannya Di Rumpin, Bogor. J. Penelit. Hutan Tanam 7(4): 201-209, 2010.

[15] Wattimena, C.M.A., Pelupessy, L. dan S. Selang. 2018. Identifikasi Jenis Hama Tanaman Damar (Agathis alba) Di Hutan Lindung Sirimau Kota Ambon Provinsi Maluku," Agrologia 5(2): 95-100. 